\title{
Man as the Measure of All Things
}

Thoughts on Moral Perfection, Finitude, and Metaethics

Jeremy Millington

\section{(2) OpenEdition}

\section{Journals}

Electronic version

URL: http://journals.openedition.org/ejpap/908

DOI: $10.4000 /$ ejpap.908

ISSN: 2036-4091

\section{Publisher}

Associazione Pragma

\section{Electronic reference}

Jeremy Millington, «Man as the Measure of All Things », European Journal of Pragmatism and American Philosophy [Online], II-2 | 2010, Online since 21 December 2010, connection on 19 April 2019. URL :

http://journals.openedition.org/ejpap/908 ; DOI : 10.4000/ejpap.908

This text was automatically generated on 19 April 2019.

\section{(c) $(1)$}

Author retains copyright and grants the European Journal of Pragmatism and American Philosophy right of first publication with the work simultaneously licensed under a Creative Commons AttributionNonCommercial-NoDerivatives 4.0 International License. 


\title{
Man as the Measure of All Things
}

\author{
Thoughts on Moral Perfection, Finitude, and Metaethics
}

\author{
Jeremy Millington
}

1 W. H. Auden stated that "the only sensible procedure for a critic is to keep silent about works which he believes to be bad, while at the same time vigorously campaigning for those which he believes to be good, especially if they are being neglected or underestimated by the public." ${ }^{1}$ Following a similar metacritical theme, he goes on to remark that the way to educate a man about his poor eating habits is not to tell him his diet is poor, but to provide him with a healthier alternative. Such metacritical advice moves against the grain of some contemporary philosophic practice, which seems to revolve around philosophic meals starting to grow rot.

2 The metaethical field, in particular, can feel something like this. Its original purpose, so far as I can tell, was to produce a systematic understanding of what goes on in ethical theory such that ethics might produce fruit. I have in mind here something like G. E. Moore's science of ethics found in the Principia Ethica: the place a number of contemporary ethical readers begin. ${ }^{2}$ Perhaps, however, this is already claiming too much for metaethics as it now stands; perhaps its goal is more distantly connected to ethical practice and moral issues. But should such a distancing between practice, theory, and meta-theory cause concern? On the one hand, the narrowness of metaethical work aims to produce a genuine philosophic understanding without conflating its subject or method with that of ethical theory and practice. On the other hand, whether or not we have theories to justify or illuminate such practices, they carry on nonetheless. That is, the exercise of moral and ethical practice imposes itself upon life, in the way that hunger does. Has metaethics fed our moral-theoretical hunger?

3 I am sympathetic to Auden's critical methodology, but there is a certain professional responsibility that demands addressing current trends in ethical debate (i.e. the metaethical debate), as well as their genealogy. I am inclined at once to participate in this exchange of criticism encompassed by the metaethical narrative and to abandon it altogether for alternative pictures. Given this tension, I propose a sort of conversation that brings into the fold some notions borrowed from the debate in metaethics along with 
those outside it - some contemporary and some classical, some philosophic and some poetic.

4 Admittedly, such a conversation will feel foreign to the analytic-argumentative styles found in (at least) some metaethical debate. It will have its own inherent limitations, as well: a certain informality and a long line of contingent propositions, in particular. However, I hope such a strategy will provide a framework for identifying some weak genes in the metaethical lineage, while simultaneously offering a more diverse, and thus a healthier, partner for the moral theorizing.

The structure of the discussion will follow these very broad lines, starting with Protagoras' notion of man as the measure of all things: If man is the measure of all things, we must consider what man is. Amongst other things, man is flux in a finite world, which means that he ${ }^{3}$ changes as a measuring stick (evolves, if you like). If man is the measure of all things, including moral questions, which picture can we use to orient ourselves? One intuition is that developing a moral practice in light of man's shifting horizon demands a similar flexibility, one that adapts. What are the conditions and criteria for adjusting practice then? My suggestion is that moral perfection, which is what adjustments to practice seek to accommodate, comes from exemplary figures, to the degree to which such figures embody an ideal, fixed standard without transcending so far beyond the reality of a finite, evolving existence as to alienate man from himself. Moral perfection bears what may be called a family resemblance to Cavell's notion of moral perfectionism, which itself grows out of an Emersonian picture - an unattained but attainable self. Aristotle is, likewise, perhaps a family member a couple steps removed, but certainly part of the lineage. But, like all family resemblances, there are important differences.

6 At least initially, this line of thought bears only a loose connection to the metaethical debate. The fundamental difference here is between the question of moral properties, which dominates metaethics in many ways, and that of moral character. The two relate in important ways: neglecting one at the expense of the other would diminish the project as a whole and on either side of the divide.

\section{A Foot}

7 If it is true, as Protagoras seems to have claimed, that man is the measure of all things, we might ask, how does one use such a measuring tool? All measurements depend upon a relation, a stretch of space from beginning to end, from lowest to highest, and from one to another. As we survey man as measure, we consider all things, but we also consider the measuring stick itself. What sort of measuring stick is man? As a ruler, it may be useful to consider the history of the instrument - a Ruler - as a sort of analogous narrative. It is instructive, however mythical, to consider the notion of a foot, in particular, as the most basic measuring tool. The foot is that point at which the human makes firm contact with the world. We might even mythologize such a development further along evolutionary lines, by which the rise of bipedal man eliminated the unity (or conflict?) between hand and foot, leaving only the latter as the surest useful measure of earthly space. The distance from be- ginning to end thus becomes the distance from heel to toe. As a standard of measurement, its objectivity fluctuates in accordance with that of the ruler the imperial footprint, as one legend suggests. Such a scale may strike us as irrational elitism, but its principle remains: man, as an embodied measure, reveals no consistent, uniformly objective standard - he has many sized feet. 
If man embodies no easy, fixed and reliable rule by which to measure all things, to measure reality, reality will appear similarly dynamic. Locke states, "The obvious portions of Extension, that affect our Senses, carry with them into the Mind the Idea of Finite." The finite is a concept easily grasped and seen in the world, as it dominates our experience. It is also perhaps unsurprising that we should seek to tame and order such a world: conceptually, scientifically, politically, militaristically, philosophically, and so forth. The world becomes an ultimately threatening place to inhabit. Its beauty and mystery are admirable and aweinspiring but poised for consumption, for remission into the individual - beauty leaves the world and retreats into the eye of the beholder. The world must be possessed and dominated in some way. The move towards concreteness becomes literally and figuratively real - the garden of Eden is paved over. If we cannot provide some fixed standard, perhaps reality and nature can do the job for us (e.g. the laws of nature, via physics, Romanticism, Thoreau). We can then graft ourselves onto this permanence - live lives free of change, free of risk, free of mystery.

9 So many projects rest upon this tension between the fixed and the unfixed (objectivity and subjectivity, transcendence and immanence, infinitude and finitude). The tension between the two is a major thread of Hegel's unfolding of the concept of Spirit, as well as Kant's understanding of God, reason and faith. Reconciling such tensions is certainly a philosophical project, if not a moral and religious one, too.

There is more to be explored in man as the measure of all things, room to inject some further qualifications. What could this look like? If we survey the great historical immensity that constitutes man, we come away with a frameless picture: contradictory, confusing, and complex in a variety of ways. It resembles something like a monumental Rothko painting with its foggy fields of color. The closer I stand to such a picture, the more in touch I am with its physical presence, its rich texture, its concrete reality. A stage of determinable but indeterminate action presents itself. Paradoxically, the closer I get, the more I distance myself from its boundaries, from the possibility of measurement, of a certain kind of understanding. Man, or as he should be called (in line with the maxim as originally written), humanity, presents a similar puzzle - of distance and measurement, of subjectivity and finitude. Humanity's history demonstrates both tremendous destructive and violent possibilities and acts of exceptional love and empathy, as well as complex moments that seem to question such a distinction altogether. If we are to measure all things - humanity included - by such a standard, what picture of humanity are we to work with? It would seem naïve at best and dangerous at worst to exclude some picture or another, however extreme. I am suggesting, ultimately, one take into account both the foot of the king and the sole of the people.

\section{Some Questions of Finitude}

11 Before considering how moral questions relate to finite, fluctuating existence, it will be of some use to consider the notion of finitude more generally. What does it mean to say that human beings and the world they occupy is a finite one? Is it a finite world? And if it is, what role does infinity play, if any?

12 Zeno's dichotomy paradox describes a story along the following lines according to Aristotle's account. Imagine that a hundred yards away, there is a bus you must catch. Being a fast runner, you catch the bus just in time. It seems clear enough that in the act of 
catching the bus, you passed a halfway point between the starting point and the bus. Between that halfway point and your starting position, we can imagine another halfway point - a quarter of the full distance. Between the quarter distance and your start point lies another halfway point. If we carry this process out, halving each half, there seems to be a potentially infinite number of halfway points between your starting position and the bus. This suggests that you crossed an infinite distance in order to reach the bus since the number of half way points can be measured indefinitely. How can one cross an infinite amount of measurable space? One can no more count to infinity than traverse such a distance. To count, to measure, is to posit a finitude.

There are a variety of solutions and conclusions one can draw from this illustration. Zeno suggests that motion is an illusion - we never actually move anywhere or traverse any distance. Conversely, the illustration might suggest that the world, the material world at least, is not an ideal realm, in the way that numbers are. So long as the world is measurable, it is finite. The ideal, the perfect, the infinite, belongs to another realm.

Locke covers similar territory in contrasting a "positive" versus a "negative" idea of the infinite:

We can, I think, have no positive Idea of any Space or Duration, which is not made up of, and commensurate to repeated Numbers of Feet or Yards, or Days and Years. And therefore, since an Idea of infinite Space or Duration must needs be made up of infinite Parts, it can have no other Infinity, than that of Number capable of still farther Addition; but not an actual positive Idea of a Number infinite. For, I think, it is evident, that the Addition of finite things together [...] can never otherwise produce the Idea infinite [...]. ${ }^{5}$

Locke thus demonstrates the discrepancy between "extensions" of actual infinite duration and those merely moving toward it, the latter being only a negative idea of infinity. Returning to the bus illustration, imagine measuring the distance covered in order to compare your speed to others'. The distance measures out to a number of stick lengths - 12.5 sticks. Does ' 12.5 ' describe the distance ideally, or "positively" in the Lockean sense? If it were exactly 12.5 sticks, then the same problem as before emerges. Within ' 12.5 ', there are an infinite number of halves, which must be measured.

The numbers that such measurements rely upon are descriptive of the distance but not perfectly equivalent. Zeno's paradox points to a discrepancy between those numbers and the physical reality to which they point. Numbers, used in this way, work as a sort of theoretical model, an approximation. Does this cease to make them useful? Measuring the distance at 12.5 sticks allows for comparisons, such as the amount of time it takes one to run 12.5 sticks under various conditions. The numerical values provide a certain framework for understanding. They are approximations of a physical reality.

William James made an analogous observation early in his development of pragmatism. He stated that "as the sciences have developed farther, the notion has gained ground that most, perhaps all, of our laws are only approximations." ${ }^{16}$ Furthermore, we might say that some approximations are better than others.

Numbers, like other theoretical tools, are useful in a sort of reverse sense as well. Rather than merely corresponding descriptively to some physical phenomenon, they help reveal possibilities (e.g. practical, technological, etc.). In sports, athletes and coaches, use measurements to assess the success of training programs. By measuring the time it takes a player to run some particular distance down to a tenth of a second, a coach will know if that player is capable of racing past the opposition. 

theory, as such, is to account for the discrepancy between the finite and the infinite. Stanley Cavell describes this discrepancy, between "the world of sense" and the intelligible world, as a "disappointment with the world." In cases of law, or "ultimate perfection," "the standard becomes incommensurable. Embracing approximations seems equally unsatisfying, however. So either the standard - the law - transcends too far beyond the reality of finite being or it remains finite and ephemeral. The task becomes the discovery of useful measuring tools and an appropriate standard of perfection that reconciles the two in some sensible fashion.

\section{Methods for Morals and Objectivity}

"The difference between verse and prose is self-evident, but it is a sheer waste of time to look for a definition of the difference between poetry and prose."

In the above quotation, I take Auden to be expressing what G. E. Moore expresses in the debate over the definability of 'good'. Moore argues that good is not definable, though we can know what it is. ${ }^{10}$ The mistake that philosophers have made up to the time of his writing, Moore says, is that they mistake 'good' for some other, natural property, like pleasure.

If systematic, philosophical ethics stands any chance, pleasure must be allowed to be pleasure, and 'good' good. In response, critics ask, how do we know that the words we use distinctly for 'good' and 'pleasure' are not actually referring to the same thing, be it natural or non-natural? How do we determine the difference without either assuming it or denying it from the beginning?

Moore's essay sparked a series of papers concerned with moral properties and definability. Consequently, some of the debate in metaethical theory focuses on the moral realm as a sort of quasi-naturalized science (or fully naturalized in some cases), ${ }^{11}$ in which the philosopher qua scientist looks for moral properties, either literally in the physical world or as non-natural properties, floating about the metaphysical realm waiting for minds to apprehend them. ${ }^{12}$ Essentially two sides emerge from this debate, one motivated by attempts to show that morality is fixed (imposed from without), the other motivated by attempts to show that morality is relative, the product of preference or whim (created from within) - and never the twain shall meet. ${ }^{13}$ 
.

for? Is 'a lot' objective or subjective? Imagine a series of circumstances in which you request 'a lot' of flowers. In the first case, you are planning a wedding with a thousand guests. The ceremony will take place in a monumental and sparsely decorated space. In the second case, you made some unfortunate comment that insulted a dear friend, and you would like to make amends. In the third and final case, you are a botanist looking to discover some particular feature that distinguishes the Mexican poppy flower from the California poppy flower. What counts as 'a lot'? Is it the same in each case? The first case seems to demand more than second case clearly enough. Though, we can imagine more specific circumstances that could threaten that assumption, too. If the offended friend was a figure of some tremendous sensitivity and, furthermore, particularly immune to gestures of apology that demand little investment of time and money, then only the most extravagant effort would truly make amends. In conjunction, if the bride and groom in the first scenario lived lives of urban isolation, having made few if any trips to the florally 
rich countryside, 'a lot' might mean something different. Does this mean that just any amount meets the standard for 'a lot'? Or that 'a lot' is not objective in some way? Yes and no. In terms of 'a lot' counting as objective in some strict, material sense, that seems to have little promise: what counts as 'a lot' is relative to particular situations. Similarly, it is contingent upon specific details.

Does contingency rule out objectivity in the softer sense? In each of these scenarios, there is a sense in which 'a lot' is contingent upon some greater purpose and set of details. Not every detail matters but some do, which must be worked out in individual cases. For the botanist, as for the wedding planner and offending friend, there will be particular amounts of flowers that will not sufficiently qualify as 'a lot.' One will not be enough and two likely will not suffice either. If we try to reduce the amount that counts as 'a lot' to some rigid material quantity (i.e. 'a thousand'), we lose the point. For the botanist, one flower will not suffice, but it is not clear that fifty or fifty-one will generate much discrepancy (both are closer to a lot than one). Will six, fifteen, or twenty-seven count? We can recognize the difference in extremes possibly, but measuring the precise moment where a quantity changes to 'a lot' is difficult to pin down without some further set of qualifications.

Objectivity seems to be threatened here. But imagine a further situation. What if I show the botanist the case of the offending friend and the wedding planner and say: "Look, a lot of different quantities can count as 'a lot,' so any amount I give you could count as 'a lot.' Take these three flowers and be on your way." The botanist may walk away perplexed and offended, possibly eliciting another complicated situation demanding the assessment of 'a lot' - a lot of explaining and apologizing. In the given situation, a lot of flowers meant something quite specific and certainly concrete: not just any number would do.

When thinking about moral objectivity and subjectivity, I suggest we follow similar lines, a line of thought that, not coincidently, also appears in Emerson. He states:

There is a man and his virtues. Men do what is called a good action, as some piece of courage or charity, much as they would pay a fine in expiation of daily nonappearance on parade. Their works are done as an apology or extenuation of their living in the world, - as invalids and the insane pay a high board. Their virtues are penances. ${ }^{14}$

This passage follows another passage in which Emerson states that "good and bad are but names very readily transferable to that or this." ${ }^{15}$ On the surface, such a proclamation may seem to suggest that 'good' and 'bad' are not objective in either sense outlined. Good and bad fluidly and arbitrarily fix and unfasten themselves. However, comparing these two passages together with a later one clarifies his position in line with a softer objectivity. He states: "Character teaches above our wills. Men imagine that they communicate their virtue or vice only by overt actions, and do not see that virtue or vice emit a breath every moment. ${ }^{16}$ Character manifests good and bad, it places it in the world. So what counts as moral cannot rigidly or blindly be reduced to some material action or property. Hume, a paragon of the empiricist model, provides valuable insight here. In moral matters, he states: "The external performance has no merit. We must look within to find the moral quality. This we cannot do directly; and therefore fix our attention on actions, as on external signs. But these actions are still considered as signs." 17 

critically to his position, is the ability to generate some method for identifying moral properties. Moore suggests bringing 'good' before the mind. An admirable suggestion, I think, but limited in its ability to generate the sort of systematic understanding of ethical practice he envisioned. And presumably the goal of this would be to aid theories of ethical practice so that decisions warranting ethical deliberation could be subject to some kind of test: does this object, act, thing, etc., possess the property of goodness, thus conferring moral worth? If the metaethical debate rests on the identification of moral properties their real, emotive, natural or non-natural existence - but fails to generate a method for identification, perhaps alternative strategies offer something more substantive. It is, after all, not the cataloging of specific quantities of flowers that constitute 'a lot' in various cases that tells me how much 'a lot' will be in future cases.

\section{Questions of Perfection}

Though a work of literature can be read in a number of ways, this number is finite and can be arranged in a hierarchical order; some readings are obviously "truer" than others, some doubtful, some obviously false, and some, like reading a novel backwards, absurd. ${ }^{18}$

It will help to recount the course of the discussion thus far to see how the pieces fit together. First, we take the premise that human beings are the measure of all things, which means that ethical questions ought to be considered in light of what humans are (and how they change). Second, humans are, amongst other things, finite beings in a finite world, which means they are not a fixed, complete thing. A shortcoming of much metaethical debate stems from its emphasis upon objectivity and subjectivity in terms of moral properties. Such an emphasis on moral properties leaves out the human element, failing to generate methods that inform practice. Part of that failure, I contend, arises from neglecting how a finite being operates in relation to ideals, which are of a different, perfect nature. Rather than searching for moral properties outside human being (in the infinite), or dismissing them altogether (reducing them to the finite), perhaps we can look for models that reconcile the two. I further suggest that such a model is better conceived in terms of character rather than properties: exemplars of moral character can generate a practice that accommodates fluctuations in experience and human being as they take on evolving shapes.

In Cities of Words, Cavell explores the idea of moral perfectionism, tracing its appearance and evolution through Emerson, Plato, and American film, amongst other strange bedfellows. The idea of moral perfectionism, he claims, begins with a sense of disappointment about the world, a difference between the world "I converse with" and the world I think, in Emerson's words. ${ }^{19} \mathrm{He}$ then poses the following question: "But if the world is disappointing and the world is malleable and hence we fell ourselves called upon for change, where does change begin, with the individual (with myself) or with the collection of those who make up my (social, political) world?"20 This represents a subtle shift toward questions of moral character and away from questions of moral properties. I have suggested that questions of moral properties are embedded in a moral discourse that emphasizes a sort of quasi-scientific or empirical search for properties in particular actions and objects, while the former demands an acknowledgement of what generates their appearance in actions and objects. Interestingly, the moral-property discourse

European Journal of Pragmatism and American Philosophy, II-2 | 2010 
develops out of a practice tangentially connected to discourse, while the latter, as Cavell notes, makes discourse the cornerstone. When Cavell begins to discuss The Philadelphia Story (Cukor 1939), he observes:

I said of moral perfectionism [...] that the issues it assesses are typically not frontpage news, not, for example, issues like abortion, euthanasia, capital punishments, whistle-blowing, plagiarism, informing, bribery, greed, scapegoat, torture, treason, rape, spousal abuse, child neglect, genital mutilation, and so on. But not every fateful moral choice, every judgment of good and bad or right and wrong, is a matter for public debate. ${ }^{21}$

His suggestion is that such issues become moral issues as they develop out of the lives of people. The public/private divide has an obvious correlate in the sense of media coverage (in the context of the film), but it also conceptually corresponds with a divide between the ideal world and one that is manifest in the finite world: what gets worked out internally, within the realm of character, comes out into the world embodied and measured. This is not to say that the actions that spring forth out of character, like abortion, euthanasia, etc., do not come to possess either objective or subjective moral properties in the end, but such questions are secondary to the primary question of what sort of person one wishes to be, that one is capable of being.

Cavell claims that the Kantian project attempts to manage this divide between a sensuous world (the finite, the imminent), in which we are bound, and the intelligible world (the infinite, the transcendent), in which we are free. ${ }^{22}$ The failure of Kant, according to Cavell, is to make the intelligible world an overbearing task master that asks me to abandon or ignore the sensuous world, which he identifies with inclination. It creates a standard of action beyond what the measured, finite self is capable of achieving.

Earlier in the book, Cavell suggests that Emersonian perfectionism "specifically sets itself against any idea of ultimate perfection." ${ }^{23}$ He goes on to state further, "To live a moral life should not require that we become Socrateses or Buddhas or Christs, all but unprovokable." ${ }^{24}$ This is itself too harsh, however. It denies each of these figures a dynamic reality - a humanity - and signals a departure too far in the opposite direction. $\mathrm{He}$ is right to absolve us of the demand for some ultimate perfection, but only with certain qualifications not offered in his reading. If Kant's position is too heavily rooted in the external, the public, and what the transcendent (the infinite) demands, Cavell's position is perhaps overly rooted in the internal, the private, and what the subjective (the individual, the finite) demands.

Bridging the divide between Kant's position and Cavell's, Stephen Mulhall points to a profoundly important development in the transcendent conception of God after Kant. In putting God "in his place" - that is, removed from the finite world - a genuine frame of reference for human character is eliminated..$^{25}$ Nietzsche and Kierkegaard inherit the consequences of this divide. Mulhall points out, "What is at stake is a matter of orientation, of the acknowledgement or denial of a frame of reference or horizon of significance capable of informing the course of a human life."26

Following the lead of Kant, and perhaps more significantly, Hegel, we might take the figure of Christ as an exemplar for the concept of ethical character established thus far, conceptually and practically. I leave open the possibility of alternative exemplars of a similar character, however. The example of Christ, as such, will be just that, an example.

Picking up this thread, Mulhall draws us back to a reconciled image of Christ that makes moral perfection not an impossibly abstract, transcendent law, either imposed upon 
humanity or far removed from it, but a means for correcting and developing moral character. He states:

Christ is the presentation of the infinite in the finite; he is not a finite messenger or natural proxy for an essentially transcendent Being, but rather transcendence incarnate. The fact of his existence tells us that God's transcendence is such that it is not only able but willing - even that it deeply desires - fully to inhabit finitude. And this utterly changes our sense of what transcendence (hence finitude, and hence moral existence) might be. ${ }^{27}$ might go about answering the call of morality. That is, more generally, what sort of questions are genuinely answerable? Some questions in mathematics, for example, seem solvable under certain conditions that we can intelligibly articulate. Some other questions seem solvable or answerable though perhaps with less obvious rigor. This range of questions may vary from more complicated math problems to, say, solving a crime, like 'who stole the baker's truck?' The methods for solving both have been developed through particular social and cultural histories. These methods for answering questions develop out of a tradition and a practice. How do these practices develop? What faculties do we make use of in accommodating alterations in our methods? Such changes are, firstly, motivated by the goal in question (e.g. to solve the equation or crime). If a practice or method fails to generate the actual culprit of a crime or at least a line-up of likely suspects, we adjust the method. Such an adjustment requires an understanding of what good answers look like and that some grounds are available for re-orienting our method to produce such answers. If we deny the ability to sense the ground, there is no use speculating about its location or features. Of course, it does not seem clear that one can deny such an ability without appealing to one. What we come to discover in, say, science 
is indeed of a different character in some important way from what we might come across in moral deliberation. That we are using fundamentally different mental faculties in science and ethical question answering is not clear: reason, rationality, experience, memory, intuition, observation, thought, etc.

The same reasons offered for discounting the conditions for moral knowledge are equally incriminating toward empirical-sense experience. That questions of science have become answerable in productive ways says nothing of the relatively recent development of particular practices, and even less of the degree to which such knowledge generating systems are limited and likely subject to substantial future correction. Our approximations will change and, preferably, improve. Small gains, which current scientific practices achieve, will only come to seem smaller and more limited, or partial, as the practice grows and adjusts in accordance with the questions it fails to answer, which are infinitely more abundant than the range of questions seemingly answered.

Moral questions proceed along somewhat analogous lines, I believe. The development of character is something that demands a perpetual process of education from one generation to the next. Or, as Cavell notes in Pursuits of Happiness, from one individual to the next. ${ }^{29}$ We are all in need of conversational partners that educate us. Dewey demonstrates something along these lines in terms of the very survival and continuation of a society. All communities and the individuals that constitute them rely upon a set of practices that a community (family, state, tribe, church) must share.$^{30}$ Answering moral questions in terms of specific acts is something like trying to achieve complete scientific knowledge outside of a practice that offers grounds for correcting the practice which generates such knowledge in the first place. A good scientific practice is capable of going about answering any questions within a certain range with a particular set of skills that lead to promising answers. Ethical deliberations and related actions will not make sense divorced from the ability to evaluate methods for answering moral questions.

If you adopt the knowledge of science and its system without understanding how that system works - why it has developed along the lines it has, the spirit of that system - you forfeit the ability to identify facts and features of reality in future cases. What I think exemplary human characters offer us in the development of ethical theory is a grounding for what is possible for guiding practice, as well as a picture of the relation between the world of the infinite, which is indeed free, and that of the finite, which is measurable and bounded. Subsequently, metaethical theory may benefit from a slightly more liberal pragmatic approach. Pragmatic in the sense of identifying the reality of human being and the need to accommodate fluctuations in experience.

Moral practice in the sense outlined here is not some special activity engaged in from time to time, but it is what orients our lives as a whole, even in the moments when we engage in activities of a different nature: creative, political, philosophic, or otherwise. Echoing Emerson again, we must see "that the virtue or vice emit a breath every moment." ${ }^{31}$ 


\section{NOTES}

1. W. H. Auden, The Dyer's Hand and Other Essays, New York, Vintage (1989), 10.

2. G. E. Moore, Principia Ethica, Mineola, NY, Dover Publications (2004).

3. I will move away from gender specific pronouns, though, for the moment, I would like to preserve something of the poetic, alliterative quality in the phrasing as a gesture toward the paper's orientation.

4. John Locke, An Essay concerning Human Understanding, New York, Oxford UP (2008), 126.

5. Locke, op. cit., 129-30.

6. Stanley Cavell, Cities of Words: Pedagogical Letters on a Register of the Moral Life, Cambridge, Belknap of Harvard UP (2004), 1-2.

7. Stanley Cavell, Cities of Words: Pedagogical Letters on a Register of the Moral Life, Cambridge, Belknap of Harvard UP (2004), 1-2.

8. Ibid., p. 3.

9. Auden, op. cit., 23.

10. See Andrew Fisher \& Simon Kirchin, Arguing about Metaethics, Oxon, Routledge (2006).

11. See John R. Searle, The Rediscovery of the Mind, Cambridge, MIT (1994).

12. See Dallas Willard, "Naturalism's Incapacity to Capture the Good Will," The Nature of Nature: An Interdisciplinary Conference on the Role of Naturalism in Science, Baylor University, Waco, TX (April 2000).

13. There are nuances to these positions that bear genuine significance but are, in the end, gradients on the same spectrum. See Fisher \& Kirchin 2008.

14. Ralph Waldo Emerson, Nature and Selected Essays, New York, Penguin (2003), 180.

15. Ibid., 179.

16. Ibid., 184.

17. This point was brought to my attention in Willard's "Naturalism's Incapacity to Capture the Good Will" (see note 12 above). David Hume, A Treatise on Human Nature, Sioux Falls, SD, NuVision Publications (2008), 341.

18. Auden, op. cit., 4.

19. Cavell (2004: 18).

20. Ibid., 3.

21. Ibid., 38.

22. Ibid., 32.

23. Ibid., 3.

24. Ibid., 26.

25. Stephen Mulhall, “'The Presentation of the Infinite in the Finite': The Place of God in PostKantian Philosophy," The Oxford Handbook of Continental Philosophy, eds. Brian Leiter and Michael Rosen, Oxford, Oxford UP (2007), 504.

26. Ibid.

27. Ibid., 497.

28. Richard T. Garner, "On the genuine queerness of moral properties and facts," Arguing About Metaethics, eds. Andrew Fisher and Simon Kirchin, Oxon, Routledge (2006), 97.

29. Stanley Cavell, Pursuits of Happiness: the Hollywood Comedy of Remarriage, Cambridge, Harvard UP (2003).

30. See John Dewey, Democracy and Education: an Introduction to the Philosophy of Education, Charleston, SC, Forgotten (2009). 


\section{ABSTRACTS}

What is the purpose of metaethics in relation to ethical theory and ethical practice in contemporary philosophical practice? Metaethics is preoccupied with (at least) three particularly fundamental concepts: (1) moral properties, (2) systematization (in Moore's sense, but also in the sense of law), and (3) the finite - this latter concept may only be evident incidentally but is fatally neglected. What is needed for a rounder philosophical picture is an account of three complementary concepts: (1) moral character, (2) the spirit of law, and (3) the infinite. Streams of thought are emerging from neglected traditions, particularly those of pragmatism and early American transcendentalism, that offer a means for reconciling these two sides. This paper brings together elements of these traditions in a sort of initiatory conversation, one that takes seriously the need for an integrated conceptual framework. This process of reconciliation allows for a liberal narrative that begins with Protagoras' notion of man as the measure of all things and ends with a quasi-Cavellian notion of moral perfection. 